\title{
Economic Drivers of Technology Enabled Health Services
}

\section{N. Chandrasekaran}

Business Analytics, Loyola Institute of Business Administration, India

A. Indira

Economics, Loyola Institute of Business Administration, India

\begin{abstract}
Technology is all pervasive today. Advancements in technology has been welcomed and applauded in the health care sector. Healthcare technologies involve both clinical as well as well as non clinical processes. The applications involve patient safety, disease surveillance, E-health records, and patient empowerment. There are now various firms which are building health applications to further help the patients, care-givers and doctors. The global economy has however seen a change in the aftermath of 2008. The downturn experienced seemed to continue well into 2017. There however seems to be a spirited feeling that the economy is on the up and better prospects are forecasted for 2018. In this background, this paper looks at the various economic factors that impact technology enabled health services.
\end{abstract}

Keywords: Technology enabled health services, Global Indicators, Prospects, Competitive forces, Constraints to growth

\section{Introduction}

"It has become appallingly obvious that our technology has exceeded our humanity" said Albert Einstein. Technology is so pervasive that it has impacted every life on this planet and thus affected all sectors of the world. Advancements in technology have made the unimaginable possible; communication speeds between two ends of the world happens in a matter of seconds and production capabilities have surpassed the days of handmade products. In case of healthcare, technologies are creating various devices, procedures, medicines that are solving health problems and create healthier living. Healthcare technologies involve both clinical as well as well as non clinical processes. The applications involve patient safety, disease surveillance, E-health records, and patient empowerment. Latest technologies in healthcare space include:

Intelligent Pills programmed to deliver targeted doses of medication.

Wearable technology like Google glass which helps in improving experience of patients and practitioners.

Interoperability communication about latest information in real time between the doctors.

Digestible sensors that transmit information about the patients to identify the disorder and customize the cure.

Video Games stimulate 3D video of patients which enable medical student to make decisions as they would on real patients.

Needleless Vaccinations and such others.

\section{Healthcare Technologies}

Technologies can help in dissolving barriers in the health care process. An IBM white paper brings forth how technologies have enabled both patients and caregivers about working with EMR's, booking appointments, understanding system responses. Today there are companies which have put together enhanced servers and storage to support the patients, hospitals and staff involved in the process. Systems are designed such that physicians do not have to wait for system responses during interactions with patients. Faster data access and application performance can help streamline and speedup business operations. 


\section{Healthcare Platforms of the World}

Healthcare platforms/Applications are vital part in developing a relationship with the physicians and patients through easy technologies. The 2015 mHealth summit ${ }^{1}$ also has the same theme "Anytime, anywhere: engaging patients and providers". Representatives from the field of medicine around the world think that this is essential to have more interactive and dynamic health experience.

- Healthcare applications that have been developed for various functionalities are such as given below:

- Prevention or healthy living - Calorie counter, Nike training club

- Symptomatic/self diagnosis - NHS Health and symptom checker, HealthTap, Medibank symptom

- $\quad$ Finding a physician - Better doctors, US Hospitals, Doctor visit manager

- Education post diagnosis- Family drug guide, Emergency Info 4Family, Health handbook.

- $\quad$ Filling prescription - CVS Pharmacy, Walgreens, LowestMed Mobile

- $\quad$ Compliance - Medicine Reminder HD with local Notifications, MediSafe - virtual pillbox.

These platforms for healthcare have been created with the intention of monitoring, tracking patient information through connected devices and to access patients information in real time. Analysis of data of helps to attend to the patients' needs in critical situations as also help in enhancing the experience of the patients and physicians. The apps help in collecting, integrating health related information including data, images and records.

\section{Global Economic Trends}

Global economic trends are critical for any business and its growth. What is more important is to understand the relevant position of the economy irrespective of its position in the business cycle! A company develops its plans keeping in mind the impact of business cycle so that it can embrace a sustainable approach to growing its business.

Figure: Global Growth

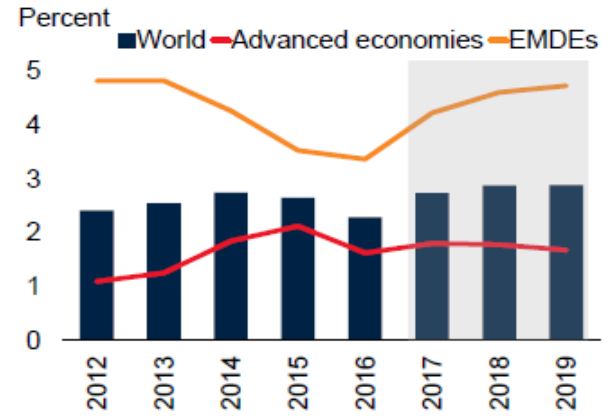

Source: Global Economic Prospects 2017, https://openknowledge.worldbank.org

It has been practice of analysts to relate overall global economic trend. When one discusses global trends, overall markets and their growth are critically evaluated. In a sense, global economy is one market which by trade reflects overall health of the market. According to the Global Economic Prospects Report published in July 2016, Growth prospects have weakened throughout the world economy. Global growth for 2016 was projected at 2.4 per cent, unchanged from the disappointing pace of 2015. Further there was a downward revision of 0.5 percentage point below the January forecast. Emerging market and developing economies (EMDEs) were facing stronger headwinds, including weaker growth among advanced

References:

http://www.mobihealthnews.com/news/mhealth-summit-2015-emphasis-ecosystem 
economies and persistently low commodity prices, as well as lacklustre global trade and capital flows. Global growth is projected to pick up slowly to 3.0 per cent by 2018 , as stabilizing commodity prices provide support to commodity exporting EMDEs. Downside risks have become more pronounced. These include deteriorating conditions among key commodity exporters, softer-than expected activity in advanced economies, rising private sector debt in some large emerging markets, and heightened policy and geopolitical uncertainties.

It may be seen from the above figure that while the financial crisis of 2007 had a deep impact, it seemed to improve after 2014 with a marginal improvement for global economy and advanced nations. For emerging and developing economies it was far more flat. However, forecast for advanced economies look better with improved global growth prospects.

Table 1: Real GDP of Major World Economies 2014 - 2019

\begin{tabular}{|l|l|l|l|l|l|l|}
\hline & 2014 & 2015 & $2016 \mathrm{e}$ & $2017 \mathrm{f}$ & $2018 \mathrm{f}$ & $2019 f$ \\
\hline World & 2.7 & 2.7 & 2.3 & 2.7 & 2.9 & 2.9 \\
\hline Advanced economies & 1.9 & 2.1 & 1.6 & 1.8 & 1.8 & 1.7 \\
\hline United States & 2.4 & 2.6 & 1.6 & 2.2 & 2.1 & 1.9 \\
\hline Euro Area & 1.2 & 2.0 & 1.6 & 1.5 & 1.4 & 1.4 \\
\hline Japan & 0.3 & 1.2 & 1.0 & 0.9 & 0.8 & 0.4 \\
\hline Emerging and developing economies & 4.3 & 3.5 & 3.4 & 4.2 & 4.6 & 4.7 \\
\hline China & 7.3 & 6.9 & 6.7 & 6.5 & 6.3 & 6.3 \\
\hline Russia & 0.7 & -3.7 & -0.6 & 1.5 & 1.7 & 1.8 \\
\hline Brazil & 0.5 & -3.8 & -3.4 & 0.5 & 1.8 & 2.2 \\
\hline India & 7.2 & 7.6 & 7.0 & 7.6 & 7.8 & 7.8 \\
\hline South Africa & 1.6 & 1.3 & 0.4 & 1.1 & 1.8 & 1.8 \\
\hline Economies grouped based on income: & & & & & & \\
\hline High income countries & 1.9 & 2.2 & 1.6 & 1.8 & 1.8 & 1.7 \\
\hline Developing countries & 4.4 & 3.6 & 3.5 & 4.4 & 4.8 & 4.9 \\
\hline Low-income countries & 6.2 & 4.8 & 4.7 & 5.6 & 6.0 & 6.1 \\
\hline BRICS & 5.1 & 3.8 & 4.3 & 5.1 & 5.4 & 5.5 \\
\hline World (2010 PPP weights) & 3.5 & 3.3 & 3.0 & 3.5 & 3.7 & 3.7 \\
\hline World trade volume & 3.7 & 2.8 & 2.5 & 3.6 & 4.0 & 3.9 \\
\hline
\end{tabular}

Source: Global Economic Prospects 2017, https://openknowledge.worldbank.org

A detailed table is presented above on Real GDP growth. Some of the inferences from the table are:

World GDP growth rate would be around 3 per cent by 2018 with uptrend from 2016. On 2010 purchasing power parity, it is likely to be at 3.7 per cent by 2018 . This would be mainly contributed by world trade growth rate from 3 per cent in 2016 to 3.7 per cent by 2018 .

Advanced economies are likely to remain stable around 1.6 to 1.8 percent. The better sentiment is due to the changed political circumstances of having a more pro-EU policy after the French elections. Japan continues to look a little damp.

Emerging and developing economies are strengthening their growth rates. In this group, BRICS shows an overall growth of $5 \%$ from 2017 onwards. China, one of the largest economy is shows more of a constant growth of around $6 \%$ which is on the slower side. Whereas Brazil, Russia and South Africa are showing signs of turnaround in 2017 and 2018. India is the only economy which shows stable and consistent growth rate of around 7.7 per cent in GDP for the period ending in 2018 based on estimates. With Goods and Services Tax being effectively implemented, this is likely to go up significantly and hence an attractive economy. BRICS growth rate largely depends upon performance of India and turnaround of Brazil, Russia and South Africa economies.

Low income countries are projected to improve their GDP growth rate by one per cent. However, experts qualify these estimates with a number of socio, economic, political and regional risks associated with these countries.

It may also be observed that world trade volume growth rate is estimated to go upto $4 \%$ in 2018 , which of course could be due to fallout of the likely protectionist policies in the advanced economies. 


\subsection{Drivers of global economic trends}

A few predicted drop in oil prices in 2014 and its likely impact on the global economic trend. Around the same time, commodity prices also dropped significantly, negatively impacting those Emerging and Developing Economies which export commodities. 2016 saw a drop in growth rate of China which also impacted Advanced Economies like United States of America, parts of Europe and other countries in BRICS which were dependent on the performance and overall health of Chinese economy.

Apart from these two factors, there were other developments which impacted the global economy. They were as follows:

While US economy continued to lead the global economy - it also has the largest trade deficit. Large economies like Germany, Japan and China are dependent on US trade policies and the appetite of its consumers to import goods and services from these nations. With the coming of the new US President, the trade policies are seeing a change.

China recorded high growth rates (double digit) for long. This was mainly because of government and state run enterprises investment rather than profits generated out of this investment. This helped them to export to developed nations. Since China did not engage with generation of domestic demand, the economy is under strain now with drop in growth rates. This is likely to continue till there is a fundamental correction to growth strategy. China is looking at other ways of doing this such as the One Belt, One Road scheme.

The collapse in Chinese growth led to severe dent in commodities market as China was one of the key buyers for basic metals, energy and even gold for private consumption. Unless commodities market revives, global economic prospects are weak. We noted this earlier when discussed about Developing and emerging economies belonging to commodity export activities.

Europe crisis is at an interesting phase with BREXIT from EU adding a new dimension. European debt crisis is a long phenomenon rather than recent history. Fundamentally, Europe is a group of economies having created an economic union with less balanced economic forces among the countries. One would have countries like Spain and Greece with high unemployment and low productivity as part of the system while Scandinavian countries, Netherlands, France, Belgium, UK and Germany having strong fundamentals. This would be structural feature affecting economic prospects in secular period. Brexit is a cause of concern! But one will have to wait for negotiations and settlement to understand full impact of exit to UK and rest of Europe and probably to the global economy.

India is emerging as new growth leader in the global economy. There is a positional advantage of demographic quotient which young and consumes more. Government policies are more open and democratic practice giving better edge to growth traction. GST would simplify business and increase GDP and further signals unification of fragmented political system for better economic management.

To conclude, global economic outlook, the economic growth rate looks stable between 3.5 to 4 per cent. Though there are a few headwinds, many expect economies to manage and remain stable at current levels of optimism to lead global economic factors.

What matters for healthcare technology providers is that it largely depends upon these two markets namely USA and BRICS nations especially India for its growth and hence well poised for growth. Unlike many other software companies which are being affected, Healthcare technology service providers is likely to be having favourable conditions which are discussed here.

\section{Prospects for Technology Enabled Health Services In Indıa}

An interesting feature of businesses in the Technology Enabled Health Services is that it lies in the interface of two broad categories in industry classification. One is the human health industry which would include all kinds of healthcare and patient care that may be required for wellbeing of the human. The other classification of the industry is the technology group which is into providing software, hardware and support through applications and servers for enabling efficient delivery of healthcare and patient care.

According to Deloitte Report, "Capitalizing on new technologies, delivery options, patient experiences and partnering across the value chain can help organizations reduce costs and propel them past their competition." 
Since technology applications derives value from healthcare, it would be more appropriate to discuss aspects of healthcare. It is seen that healthcare spend across the globe varies widely on per capita basis.

Countries like USA, Netherlands, Australia, Canada, Germany and Japan spend high amounts of per capita expenditure on healthcare with USA way ahead of other at US $\$ 9146$.

Brazil (\$1083) spends more than China (\$367) and India (\$61).

For businesses, wide variations show huge opportunities.

As a strategy for a company one will have to see how such variations can be exploited for growth of the business. Size by itself cannot define the opportunity. It has to be read along with other perspectives.

In general, healthcare costs continue to rise in the U.S. and throughout the developed world. The global health expenditure as of 2014 based on per capita spend of US \$ 948 (WHO estimate) is about US \$ 6.5 trillion (http://www.who.int/mediacentre/factsheets/fs319/en/). For instance, total U.S. health care expenditures were estimated to be $\$ 3.24$ trillion in 2015 , and are projected to soar to $\$ 3.78$ trillion in 2018. The health care market in the U.S. in 2015 included the major categories of hospital care ( $\$ 1,031.1$ billion), physician and clinical services ( $\$ 640.3$ billion), dental services ( $\$ 119.1$ billion) and prescription drugs ( $\$ 328.4$ billion), along with nursing home and home health care (\$253.6 billion).

\subsection{Competitive forces:}

Each of the segments in healthcare industry like hospital care; physical and clinical services; dental services; prescription drugs and home health care would have independent competitive forces and industry level task forces influencing them. To quote Bain Report on future of healthcare industry in 2020": "The basis of competition in the marketplace will change as well. Different therapeutic areas will be affected in distinct ways by two significant trends: growing consumer engagement and increasing standardization of care ("protocolization").

With more information about treatments available to an increasing number of consumers or patients around the globe, every company with a product to sell must understand how best to engage with consumers, in a way that speaks to their individual needs and patient experience. Search engines have produced a vast engaged patient population that one could not have imagined even 10 years ago: $80 \%$ of Internet users now search for health information online, and more than half look for specific information about a medical treatment or disease.

The demand for more engagement is not limited only to the US and Europe. Mobile phones and Internet access are now available in most emerging economies. While there will continue to be cultural differences in the way consumers engage with their care, the degree of engagement itself will only intensify globally. More than one-third of Indians, for example, currently use the Internet to search for health information, with similar percentages of younger, more educated people seeking health information online in Brazil, Mexico and China.

US providers have been somewhat slower to embrace clinical protocols than their European or Asian counterparts, but there is little doubt about the direction of this change. No longer will the individual physician be the lone decision maker. The cottage industry of medical care is being industrialized, as payers and providers increasingly align their businessesand results-which may be threatening to some, but may well produce better care at lower cost.

The above clearly brings out that the industry would depend upon on (i) Customization and (ii) Standardization.

\section{Expected drivers of growth for Industry in India:}

\section{Demographics:}

Population growth - Population growth is a natural phenomenon as countries manage population growth and stress on strategic resources by constantly looking out for efficient and effective deployment of the resources and use of advanced technology. Health care sector would be no different.

\footnotetext{
${ }^{1}$ Bain Report Healthcare Industry 2020
} 
Aging population - Most countries are aging fast and a substantial portion of population is of age 60 years and above India is the only country which has advantage of youth quotient. However, this would not be a limiting factor.

Lengthening life expectancy - With better technology and medical care average life expectancy has gone up. According to WHO: "People everywhere are living longer, according to the "World Health Statistics 2014" published today by WHO. Based on global averages, a girl who was born in 2012 can expect to live to around 73 years, and a boy to the age of 68 . This is six years longer than the average global life expectancy for a child born in 1990." ${ }^{1}$ This would positively influence the sector.

Increases in chronic diseases: Obesity, cardiovascular diseases, hypertension, and dementia are becomong common. Wide spread health problems because of increase in longvity of life and affordabiity are becoming achallenge for healthcare service providers. Diabetes is increasing with India leading in diabetes population. Resultant problems like reneal issues, eye care, cariovascular and limbs related because of diabetes demand healthcare demand and its infrastructure. Fight against communicable diseases continues especially in less developed low income economies.

Access: This is a supply side constraint. With the demographic factors influencing the demand for health care services, the number of physicians and support system to provide the same in all parts of the world is limited. The capacity to add infrastructure like hospitals, clinics, laboratories and health care education are capital intensive and time consuming. Further flow of capital to such a sector has to be balanced through private and public investments. Developing economies face a challenge and especially vast economies like India and China with sizeable portion of population living in rural areas, the challenge is likely to be huge.

Rising wealth: Global wealth reached 250 trillion US dollars in 2015. Rising wealth is contributed by US and China. Wealth is (nevertheless) still predominantly concentrated in Europe and the United States. However the favourable factor the increased middle class population - about 92 million in US and 109 million in China who would like to lead experience of change in consumption patterns and societal factors. Thus, one would expect demand for health care to go up because of this factor.

\subsection{Expected constraints to growth:}

Economic and political uncertainty: Economic uncertainty, Eurozone crisis and currency devaluation are expected to impact spending. However, India would lead the way at 16.1\% growth by 2019 (Deloitte).

Price and value based care: Today's consumers are more informed and financially sensitive while they take healthcare decisions. They have higher expectations for the services and products they receive. Consumers place high value for convenience, amenities and integrtaed service and whilesome experience in adition to traditional clinical support. Changing customer expectations are pushing helthcare service providers on collaborative models driven by technology solutions.

Reforms: Healthcare reforms in three leading economies are highlighted here:

The largest market - USA was influenced by Affordable care Act (Obama care) and implementation of the "Cadillac tax". Affordable Care Act widened the insurance net to bring more people under health insurance coverage and imposed penalty on corporations who failed to provide cover. Further it brought revenue which could be used for covering incremental insurers brought under the scheme. The Federal poverty line multiple was formed as basis for states to implement the insurance for healthcare service. The law also provided scope for reducing costs especially of public spend by transferring to insurance exchanges and companies and employers. But this seems to be under a cloud because of the new presidency.

Reforms in China focus on improving not only volume of healthcare spend through public but more importantly on quality and effectiveness of resources spent.

In India the government initiatives to restructure public spend on healthcare activities would significantly increase the volume and intense urge on government and private to use technology would see major impact on healthcare sector.

\footnotetext{
1 http://www.who.int/mediacentre/news/releases/2014/world-health-statistics-2014/en/
} 
Cost pressures: All over the globe, health care costs have gone up because of pressure on resources and general inflationary trend especially in niche service areas. The mismatch in demand and supply conditions which trend both at operating level and strategic level in health care sector would make cost pressures mount. The patients seek better financing of health care services to manage these pressures which are discussed in the subsection later here.

\subsection{Financing of healthcare:}

Healthcare sector is estimated at about 10 per cent of global GDP and one of the largest industries. Increasing cost of healthcare service brings pressure on financing pattern. Normally, healthcare spend happens through public (government) spending, insurance and private spend. The table below gives pattern of funding for healthcare spend.

Table 2: Health Expenditures in Major Economies

\begin{tabular}{|l|l|l|l|}
\hline & Out of Pocket & Public & Private Insurance \\
\hline EM Economies & 35.8 & 52.5 & 11.5 \\
\hline Asia Ex-Japan & 34.5 & 54.9 & 10.4 \\
\hline China & 33.8 & 55.8 & 10.3 \\
\hline Latin America & 32.1 & 52.6 & 15.1 \\
\hline India & 58.2 & 32.2 & 9.5 \\
\hline Advanced Economies & 14.7 & 61.1 & 24.1 \\
\hline U.S. & 11.8 & 47.1 & 41.1 \\
\hline Euro Area & 14.1 & 76.1 & 9.7 \\
\hline
\end{tabular}

Source : http://siteresources.worldbank.org/INTHSD/Resources/topics/Health-Financing/HFRChap1.pdf

Except USA, all other economies have poor insurance based financing.

In USA where the healthcare per capita spend is as high as \$US 9413 compared to double digit level in India, out of pocket expense is only less than 12 per cent. Hence public spend and insurance would demand more efficiency and effectiveness through collaborative technologies and systems.

Euro Area largely depends upon government as high as 76 per cent and is spent by government.

China is better than India to the extent that government spends more than individuals. India has poorest record of government spend and insurance. However, with healthcare spend likely to increase by 18 per cent per annum efficiency and effectiveness is important. With further limitations on capital and inability to quickly build infrastructure by government alone, Private - Public partnership model and private investment becomes important.

5.5 Infrastructure Needs: In a country like India and many other developing nations infrastructure would play a significant role in improving effectiveness of healthcare delivery especially in rural areas.

Table 3: Changing Strategies for Healthcare

\begin{tabular}{|l|l|}
\hline From & To \\
\hline $\begin{array}{l}\text { Department- and specialty driven } \\
\text { organization of care }\end{array}$ & $\begin{array}{l}\text { Multidisciplinary, multispecialty driven } \\
\text { organization of care }\end{array}$ \\
\hline Episodic and high acuity focus & Disease and cross-continuum focus \\
\hline Provider centric experience & Patient-centric experience \\
\hline $\begin{array}{l}\text { Individual physician or specilty orientation to } \\
\text { care delivery }\end{array}$ & $\begin{array}{l}\text { Team orientation to care delivery that involves } \\
\text { multiple specialties, APPs, social workers, etc. }\end{array}$ \\
\hline $\begin{array}{l}\text { Management of the high acuity portion of } \\
\text { care }\end{array}$ & $\begin{array}{l}\text { Collaboration with external partners to optimize } \\
\text { site and level of care }\end{array}$ \\
\hline
\end{tabular}

Source: "The strategy that will fix healthcare", Harvard Business Review, October 2013 
The above table clearly shows that future of healthcare is going to patient centric Apps and collaboration with third parties would drive the business.

Structural changes refer to service providers in relation to service seekers. This may include infrastructure created by government, private and in collaboration with each other and financing of healthcare spend like insurance and subsidies.

Second, one would consider technology infrastructure. This includes availability of bandwidth, favourable of policies towards development of technology especially towards information services sector and medical policies.

Third, wide adoption of broadband and mobile communications and usage of smart phones in rural and urban areas would be another significant influencer for healthcare service collaboration across stakeholders.

This would demand that healthcare stakeholders will need to work more collaboratively and operate more efficiently, lower their unit costs, raise their quality levels, and identify ways to optimize the value of their limited resources.

\section{Conclusion and Roadmap}

To summarise, opportunity factors for health care aggregators are:

- Demand side factors:

- Demographic trends,

- Increase need for chronic and communicable disease management

- $\quad$ Rising wealth

- Supply side factors:

- $\quad$ Limited access and capital requirement

- Adoption of technology for effective utilization of resources

- Threats to industry could be:

- Economic and political uncertainty: growing protectionism in countries around the world

- Customer expectations and value for money

- Cost pressures reducing affordability.

To conclude, it can be seen that those technology enabled service providers that have been early movers seem to be in the high opportunity market. Ability of the management to speed up its growth and experience and ensuring effective community building for its future value creation are going to be driving their performance.

Passionate culture, effective employee engagement, effective capital deployment and motivated (obsessed) leadership would be critical success factors. Management must build strong barrier to avoid competition to highjack the opportunity spectrum. 